\title{
Rumo à justiça social: mediação de conflitos como estratégia para prevenir a violência escolar e aprender a conviver
}

\author{
Towards social justice: conflict mediation as a strategy for preventing school violence and learning \\ to live together
}

Rumbo a la justicia social: la mediación de conflictos como estrategia para prevención de la violencia escolar y para aprender a convivir

\begin{abstract}
Resumo
As sociedades democráticas devem implementar uma escola justa, entendendo como tal aquela que garante a todos os jovens em formação a melhora das suas capacidades e atributos, bem como a promoção da autoestima e da motivação para a aprendizagem. Essa visão vai além da suposta igualdade de oportunidades que leva em conta apenas que todos tenham acesso à escola, mas que perpetua a desigualdade social. É necessário que os sistemas educacionais promovam políticas que apoiem a convivência, evitando atitudes conflituosas, mais ou menos violentas. O conflito é inerente à vida e pode levar a situações de confronto se não houver uma resolução efetiva.Um dos objetivos do sistema escolar é gerar nos alunos atitudes para compreender as situações de conflito e buscar soluções para resolvêlas, baseadas no diálogo e na cooperação, capazes de assegurar a convivência e erradicar a violência dos centros escolares, aspectos indispensáveis para que a escola seja justa. $\mathrm{O}$ artigo apresenta uma pesquisa de doutorado de 2018 na qual foi analisada a história oral de vida de dezessete professores e professoras de Campinas e nove da Catalunha. Trata-se de uma pesquisa qualitativa com base em entrevistas individuais que fizeram referência à sua atitude perante os conflitos nas salas de aula, à forma de prevenir as situações de violência, bem como ao exercício da microjustiça a partir de experiências de mediação que permitem a aquisição de competências para gerir de forma positiva os conflitos e que possam concretizar no futuro o exercício da cidadania ativa em uma sociedade democrática.
\end{abstract}

Palavras-chave: Conflito; Resolução de conflitos; Mediação; Justiça social; Cidadania democrática.

\begin{abstract}
Democratic societies must implement a fair school, understanding as such that one guarantees all young people in training the improvement of their abilities and attributes, as well as the promotion of self-esteem and motivation for learning. This vision goes beyond the supposed equality of opportunity that only takes into account that everyone has access to school, but that perpetuates social inequality. It is necessary that educational systems promote policies that support coexistence, avoiding conflicting attitudes, more or less violent. Conflict is inherent in life and can lead to confrontational situations if there is no effective resolution. One of the goals of the school system is to generate attitudes in students to understand conflict situations and seek solutions to resolve them, based on dialogue and cooperation, capable of ensuring coexistence and eradicating violence from school centers, essential aspects for the school to be fair. The article presents a doctoral research from 2018 in which the oral life history of seventeen male and female professors from Campinas and nine from Catalonia was analyzed. This is a qualitative research based on individual interviews that referred to their attitude towards conflicts in classrooms, how to prevent situations of violence, as well as the exercise of microjustice based on mediation experiences that allow for acquisition of skills to manage conflicts in a positive way and that can materialize in the future the exercise of active citizenship in a democratic society.
\end{abstract}

Keywords: Conflict; Conflict resolution; Mediation; Social justice; Democratic citizenship.

\section{Resumen}

Las sociedades democráticas deben implementar una escuela justa entendiendo como tal la que garantiza a todos los jóvenes en formación que puedan optimizar sus capacidades y atributos, así como el fomento de la autoestima y la 
motivación por el aprendizaje. Esta visión supera la supuesta igualdad de oportunidades que solo tiene en cuenta que todos tengan un puesto escolar, pero que perpetua la desigualdad social. Es necesario que los sistemas educativos promuevan políticas que vertebren la convivencia evitando actitudes conflictivas, más o menos violentas. El conflicto es inherente a la vida que puede dar lugar a situaciones de enfrentamiento si no hay una resolución efectiva de la conflictividad. Uno de los retos del sistema escolar es generar en el alumnado actitudes para comprender situaciones de conflicto y buscar soluciones para resolverlas, basadas en el diálogo y la cooperación que asegure la convivencia y erradique la violencia en los centros escolares, aspectos indispensables para que la escuela sea justa. El artículo presenta una investigación doctoral de 2018 en la que se analizó la historia oral de vida de diecisiete profesores y profesoras de Campinas y nueve de Catalunya. Se trata de una investigación cualitativa basada en entrevistas individuales que hacían referencia a su actitud ante los conflictos que se generan en las aulas, la forma de prevenir situaciones de violencia, así como el ejercicio de la micro justicia a partir de experiencias de mediación que permitan la adquisición de competencias para gestionar conflictos de manera positiva que podrán implementar en el futuro para ejercer una ciudadanía activa en una sociedad democrática.

Palabras clave: Conflicto; Resolución de conflictos; Mediación; Justicia social; Ciudadanía democrática.

\section{Introdução}

Se a educação orientada à justiça social deve estar relacionada à consecução da justiça na e através da educação (Bolívar, 2012), o que seria uma escola justa? Para tentar responder a essa pergunta, Dubet (2004) parte do princípio de que a institucionalização do mérito nas sociedades democráticas estabelece que cada um, em decorrência de seus esforços e dos seus atributos, possa ser bem-sucedido; contudo, tal princípio estabelece como pressuposto que "[...] A escola é gratuita, os exames são objetivos e todos podem tentar a sorte. O quadro formal da igualdade de oportunidades e do mérito foi globalmente instalado em um grande número de países.” (Dubet, 2004, p. 542), de modo que, em âmbito escolar, o mérito não tornou a escola mais justa, mas permitiu que todos participassem da mesma competição.

Assim, embora a expansão da educação tenha tornado a escola mais acessível, Dubet $(2003,2004)$ não acredita que esse processo a tornou mais justa; antes, a defesa da meritocracia na escola perpetuou as desigualdades sociais em seu interior, produzindo as suas próprias (desigualdades), que para ele abrangem: a escolha e transmissão dos conteúdos, as baixas expectativas dos professores em relação às famílias desses alunos, a maior rotatividade de professores nos bairros considerados difíceis e a todas as demais vulnerabilidades presentes no entorno do espaço escolar pela ausência do Estado e de políticas públicas (Dubet, 2003).

Para Dubet $(2003$, 2004), as desigualdades escolares são expressão do tratamento desigual dispensado aos alunos menos favorecidos, pois, ao reforçar o "modelo de igualdade de oportunidades meritocrático", a escola contribui para aprofundar ainda mais a ideia de que os alunos que fracassam são os únicos responsáveis pelo seu próprio fracasso, uma vez que a escola concede a todos as mesmas oportunidades. No entanto, os alunos "vencidos" nessa competição são abandonados pela escola; ademais, uma vez convencidos de ser esta uma competição justa, os comportamentos daí decorrentes variam desde a perda da autoestima e da motivação, sucessivas retenções, e até mesmo a recusa em prosseguir os estudos. Ainda de acordo com Dubet (2004, p. 104):

Uma escola justa não pode, portanto, se limitar a construir uma competição equitativa, ela deve também tratar os vencidos de maneira justa a fim de que não oscilem entre o retraimento, a agressão e o ódio de si. A violência escolar não é unicamente o produto da crise social e da delinquência dos alunos; quando é antiescolar, ela é também uma resposta à violência muito particular à qual se submetem os alunos levados a perder toda a autoestima, fazendo voltar o estigma contra aqueles que o estigmatizaram.

As violências identificadas no contexto escolar têm afetado as vidas dos professores, dos estudantes e o próprio cotidiano das escolas, colaborando para que a escola venha se configurando como um espaço do medo, do desânimo, da impotência. Sentimentos que são apresentados sob a forma de indicadores expressos na Pesquisa Internacional sobre Ensino e 
Aprendizagem $\left(\right.$ Talis $^{I}$ ), coordenada em âmbito internacional pela Organização para Cooperação e Desenvolvimento Econômico (OCDE) e organizada pelo Instituto Nacional de Estudos e Pesquisas Educacionais Anísio Teixeira (INEP), entre os anos 2017 e 2018, na qual o Brasil liderou o ranking de violência no ambiente escolar.

Nesta investigação, diretores de escolas brasileiras, públicas e privadas, indicaram que $28 \%$ das instituições que ofertam os anos finais do ensino fundamental registram situações de intimidação entre os estudantes, semanal ou diariamente, situação que também se destaca para $18 \%$ dos gestores do ensino médio. Interrogados sobre como se sentem diante das situações de violência, $18,8 \%$ dos docentes dos anos finais do ensino fundamental informaram que os casos de intimidações ou abusos verbais são bastante estressantes para eles. Outros 17,2\% apontaram a vivência de situações desse tipo como muito estressantes. Já entre os professores do ensino médio, 16,3\% afirmaram que casos desse tipo geram bastante estresse e 14,1\% afirmaram ficar muito estressados quando são intimidados ou abusados verbalmente (INEP, 2019).

As percepções desses professores sobre a violência escolar encontram respaldo na pesquisa realizada pelo Instituto Locomotiva, a pedido do Sindicato dos Professores do Ensino Oficial do Estado de São Paulo (APEOESP, 2014; 2017; 2019). De acordo com os últimos dados apresentados, mais da metade dos professores da rede pública estadual de São Paulo (54\%), afirmaram já ter sofrido algum tipo de violência nas escolas em que trabalham; estes dados apontam um aumento quando comparadas com os $51 \%$ da pesquisa realizada em 2017, e com os dados de 2014, na qual esse percentual era de $44 \%$. Entre uma pesquisa e outra, o percentual dos professores que identificavam suas escolas como violentas passou de 57\% (2014), para $71 \%$ (2019). Entre os estudantes, 37\% relataram terem sofrido violência na escola em que estudam. Ainda de acordo com os dados da pesquisa, os professores informam que são majoritariamente vítimas de agressão verbal, enquanto os estudantes sofrem mais bullying (APEOESP, 2019). Os impactos dessa realidade têm conduzido ao afastamento dos profissionais da educação da sala de aula. De acordo com Paixão (2019, s/p), "por dia, 111 professores da rede estadual de São Paulo foram afastados por transtornos mentais ou comportamentais. Na ponta do lápis, o ano de 2019 já soma 27 mil licenças médicas por esses motivos até o mês de agosto".

A presença de violência nas escolas públicas brasileiras também foi apontada por $70 \%$ dos jovens participantes do Diagnóstico participativo das violências nas escolas: falam os jovens, investigação realizada em 2016 e que buscou verificar sua percepção sobre a violência escolar e do seu entorno, por meio de uma parceria entre a Faculdade Latino-Americana de Ciências Sociais (FLACSO), a Organização dos Estados Ibero-americanos para a Educação, a Ciência e a Cultura (OEI) e o Ministério da Educação (MEC), em 7 capitais do País². Nesta, um terço dos alunos indicaram a discriminação dentre as situações de violência mais vivenciadas na escola, em áreas pertencentes aos direitos humanos, a saber: política, territorial, pessoas com deficiência física, gênero, classe social, étnico-racial, orientação sexual e religião (Abramovay, Castro, Silva \& Cerqueira, 2016, p. 34-40; Pereira, 2020).

Esses dados evidenciam que ainda se constitui como um grande desafio para a instituição escolar tornar possível a resolução dos conflitos e a prevenção da violência em seu interior. Neste sentido, os modelos de microjustiça têm sido apontados como alternativas consistentes nas situações envolvendo conflito e violência em âmbito escolar: ao propor, por meio do diálogo, a reparação ao invés da punição, e a responsabilização ativa dos estudantes, estas propostas atrelam à sua ação o desenvolvimento de uma postura de respeito à alteridade e aos direitos humanos, donde se depreende a potência da parceria entre justiça e educação.

Aspecto que já havia sido evidenciado no Programa Nacional de Direitos Humanos (Secretaria Especial de Direitos Humanos da Presidência da República, 2009 [PNDH-3]), ao contemplar na diretriz 19, que o compromisso com o fortalecimento dos direitos humanos e dos princípios democráticos no contexto de educação formal deva ocorrer por meio do

${ }^{1}$ Talis é a sigla em inglês de Teaching and Learning International Survey (INEP, 2019).

${ }^{2}$ As 7 capitais que participaram dessa pesquisa foram: Maceió (AL), Fortaleza (CE), Vitória (ES), Salvador (BA), São Luís (MA), Belém (PA) e Belo Horizonte (MG). 
"[...] desenvolvimento de estratégias de mediação de conflitos e de Justiça Restaurativa nas escolas, e outras instituições formadoras e de ensino superior, inclusive promovendo a capacitação de docentes para a identificação de violência e abusos contra crianças e adolescentes, dando o devido encaminhamento e a reconstrução das relações no âmbito escolar (Brasil, 2009, p. 156). Compromisso que também encontra respaldo no disposto na Base Nacional Comum Curricular (Ministério da Educação [MEC], 2018, p. 478-479), que estabelece que a parte flexível do currículo deva contemplar como eixo estruturante a “[...] mediação e intervenção sociocultural: [que] supõem a mobilização de conhecimentos de uma ou mais áreas para mediar conflitos, promover entendimento e implementar soluções para questões e problemas identificados na comunidade."

Donde se percebe que a promoção da mediação de conflitos no âmbito educacional é particularmente fecunda para a elaboração de um projeto formativo engajado em favor de uma cultura alicerçada nos ideais e valores da democracia, dos direitos humanos, da justiça social e da formação de sujeitos aptos ao exercício ativo da sua cidadania.

Nessa perspectiva, é importante destacarmos que os dados apresentados pelo "Mapa da Violência: os jovens do Brasil" (Waiselfisz, 2013, 2014, 2015), como também no "Atlas da Violência" (Instituto de Pesquisa Econômica e Social Aplicada [IPEA], 2017, 2019), evidenciam serem os jovens a parcela da população mais suscetível ao fenômeno da violência. Não obstante ambos os documentos apresentem uma diminuição dos índices de violência fatal contra os jovens no Estado de São Paulo, esses dados referem-se principalmente às mortes por homicídio, e não às violências físicas e simbólicas sofridas pelos jovens no interior das instituições educativas. As estatísticas apresentadas tanto pelo Sindicato dos Professores do Ensino Oficial do Estado de São Paulo (APEOESP, 2014, 2017, 2019), como as ocorrências policiais registradas por estes profissionais e divulgadas por meio da Lei de Acesso à Informação ${ }^{3}$, corroboram estas percepções.

O município de Campinas-SP ocupou a quinta posição em registros de ocorrência policial registrada por professores ${ }^{4}$. Neste contexto, a Secretaria Estadual de Educação realizou o curso sobre justiça restaurativa intitulado: "Cultura Restaurativa e suas Práticas", através de uma parceria entre a Secretaria de Educação do Estado de São Paulo (SEE-SP), a Vara da Infância e Juventude de Campinas (Tribunal de Justiça - TJ/SP), e a Federação das Entidades Assistenciais de Campinas (FEAC), entre os meses de agosto e dezembro de 2014, para professores e gestores da rede pública estadual.

Se o uso das práticas restaurativas tem sido estimulado pela Secretaria de Educação do estado de São Paulo para prevenção da violência e para mediação dos conflitos no ambiente escolar, seja entre os alunos ou entre os alunos e os professores, de que maneira elas têm colaborado para o arrefecimento da violência praticada neste lócus?

Importante destacar que a iniciativa de abordar esta questão tem sua origem na pesquisa de Doutorado, realizada pelo Programa de Pós-Graduação em Educação, defendido em 2018, no qual mapeamos a história oral de vida 17 professores da estadual paulista de educação, após seu egresso do curso de formação "Cultura Restaurativa e Suas Práticas". Uma parte destes estudos foi realizado na Universitat Autónoma de Barcelona (UAB) ${ }^{5}$, pois a região da Catalunha, na Espanha-ES, utiliza desde 2009, técnicas de mediação de conflitos não somente na rede pública, mas em todos os centros do sistema educativo para prevenção da violência e dos conflitos no ambiente escolar. Não obstante as diferenças entre as culturas brasileira e catalã, compreender sua realização e identificar experiências bem-sucedidas, constituíram objeto da pesquisa realizada no intercâmbio por meio do mapeamento da história oral de vida de nove professores catalães, cujos principais resultados apresentamos neste artigo.

\footnotetext{
${ }^{3}$ A Lei de Acesso à Informação foi publicada na Folha de São Paulo. http://www1.folha.uol.com.br/educacao/2017/09/1919146-sp-tem-quase-2-professoresagredidos-ao-dia-ataque-vai-de-soco-a-cadeirada.shtml E também foi publicada no Brasil de Fato. https://www.brasildefato.com.br/especiais/a-cada-dia-maisde-100-professores-sao-afastados-por-transtornos-mentais-em-sp

4 Precedida apenas pelas seguintes cidades: São Paulo (capital), Grande São Paulo (excluída a capital), Bauru e Ribeirão Preto. http://www1.folha.uol.com.br/educacao/2017/09/1919146-sp-tem-quase-2-professores-agredidos-ao-dia-ataque-vai-de-soco-a-cadeirada.shtml

5 Embora a universidade se chame Universitat Autònoma de Barcelona, destacamos que está localizada a $25 \mathrm{~km}$ da cidade de Barcelona, mais especificamente na cidade de Cerdanyola del Vallès.
} 
Sua relevância consiste em ser este um tema que tem mobilizado a comunidade educacional e a sociedade, não só a brasileira, mas também a espanhola, tendo-se em vista não apenas a compreensão do fenômeno social da violência escolar e de suas consequências no interior das instituições escolares, mas, sobretudo, pelo próprio conteúdo das políticas orientadas à sua prevenção e a forma pela qual estas vêm sendo executadas.

\section{Metodologia}

Quando a investigação no contexto do doutorado-sanduíche foi realizada, em 2017, já havíamos concluído a pesquisa de campo da investigação do doutorado, realizada entre os meses de abril de 2015 e junho de 2016; nesta, o objetivo geral consistiu em compreender, a partir das suas narrativas, e após sua participação na formação continuada "Cultura Restaurativa e Suas Práticas", o lugar que os direitos humanos e a justiça têm na história oral de vida de 18 professores em efetiva regência de classe na cidade de Campinas-SP.

A investigação foi desenvolvida sob o enfoque qualitativo, com base em entrevistas gravadas e analisadas a partir do referencial teórico-metodológico da história oral de vida, adotado nesta investigação, por considerarmos que esta proposta nos permite captar “[...] os condicionantes das vivências individuais” (Meihy, Holanda, 2007, p. 132), a partir da apreensão das narrativas e da percepção subjetiva dos professores.

Não obstante as diferenças entre as culturas brasileira e espanhola, o uso das técnicas restaurativas em Catalunha-ES já está sendo colocada em prática há algum tempo, o que nos permite pensar formas outras para sua implementação na realidade brasileira. Metodologicamente, pesquisamos como se situam, desde a perspectiva dos professores, as noções de direitos humanos, cidadania e mediação de conflitos em suas vidas e no exercício da sua profissão. Com o propósito de encontrar respostas para as questões enunciadas, foram definidos como objetivos específicos: ouvir a história oral de vida dos professores catalães; analisar os marcos de referência que orientam a execução de práticas de mediação dos conflitos no interior das unidades escolares catalãs; conhecer a abordagem da mediação de conflitos utilizada nas escolas públicas e semipúblicas $^{6}$ na área metropolitana de Barcelona-ES.

Por esta razão, definimos como "comunidade de destino 7 ", os professores egressos da Universitat Autónoma de Barcelona (UAB). Delimitamos como "colônia", os professores que se encontram em efetiva regência de classe no ensino secundário catalão: duas escolas estão situadas na cidade de Barcelona-ES, e as outras quatro estão localizadas no seu entorno metropolitano. Para definir as redes $^{9}$ de pessoas que participaram do projeto de pesquisa, adotamos como critério professores que lecionam a disciplina "educação para a cidadania", e para seleção dos "colaboradores ${ }^{10 ", ~ p r o f e s s o r e s ~ q u e ~ e x e r c e m ~ a ~}$ docência em escolas que representam a tipologia das escolas públicas ou semipúblicas existentes na região da Catalunha; nesse sentido, as 6 unidades escolares visitadas para realização da pesquisa estão localizadas no perímetro urbano situado ao norte, ao sudoeste, na região litorânea, na região montanhosa e no centro da cidade de Barcelona-ES. De uma maneira geral, estes territórios são caracterizados pela diversidade na perspectiva territorial, multicultural e socioeconômica, como se pode verificar na figura 1. O quantitativo de professores que participaram da pesquisa foi definido em conformidade com essas informações e também pela disponibilidade em conceder-nos a entrevista.

${ }^{6}$ Das escolas visitadas, somente o Instituto Pere Calders e o Instituto Joaquim Pla i Farreras, são da rede pública. As demais escolas, a saber: Escola Sadako, Escola Pia de Catalunya, Escola FEDAC, e a Escola Sant Felip Neri são concertadas, ou seja, são de titularidade privada, mas têm um aporte econômico do Governo da Catalunha e funcionam como se fossem escolas públicas.

${ }^{7}$ Segundo Meihy e Holanda (2007, p. 51, 52), a "comunidade de destino" delineia o grupo com o qual o projeto de pesquisa dialogará, caracterizado pela vivência de "[...] dramas comuns, coetâneos, vividos com intensidade e consequências relevantes, episódios que alteram no porvir o comportamento pretérito, rotineiro, e que impõem mudanças radicais na vida grupal." (Meihy, Holanda, 2007, p. 51).

${ }^{8}$ Já o conceito de "colônia" é definido por estes autores como um recorte das características comuns dos colaboradores integrantes da "comunidade de destino" e que os interligam, tendo-se em vista a viabilidade da pesquisa (Meihy, Holanda, 2007, p. 52, 53).

9 A definição de "rede" enseja recortes ainda mais específicos, com o objetivo de se constituir como subsídio para captar a diversidade de opiniões e concepções intrínsecas à "comunidade de destino". (Meihy, Holanda, 2007, p. 54).

${ }^{10}$ Em história oral entende-se que o entrevistado colabora ativamente na condução do projeto de pesquisa, pois a sua narrativa, após ser submetida aos processos de transcrição, textualização e transcriação, deve ser submetida ao seu crivo e aprovação (Meihy, Holanda, 2007, p. 60). 


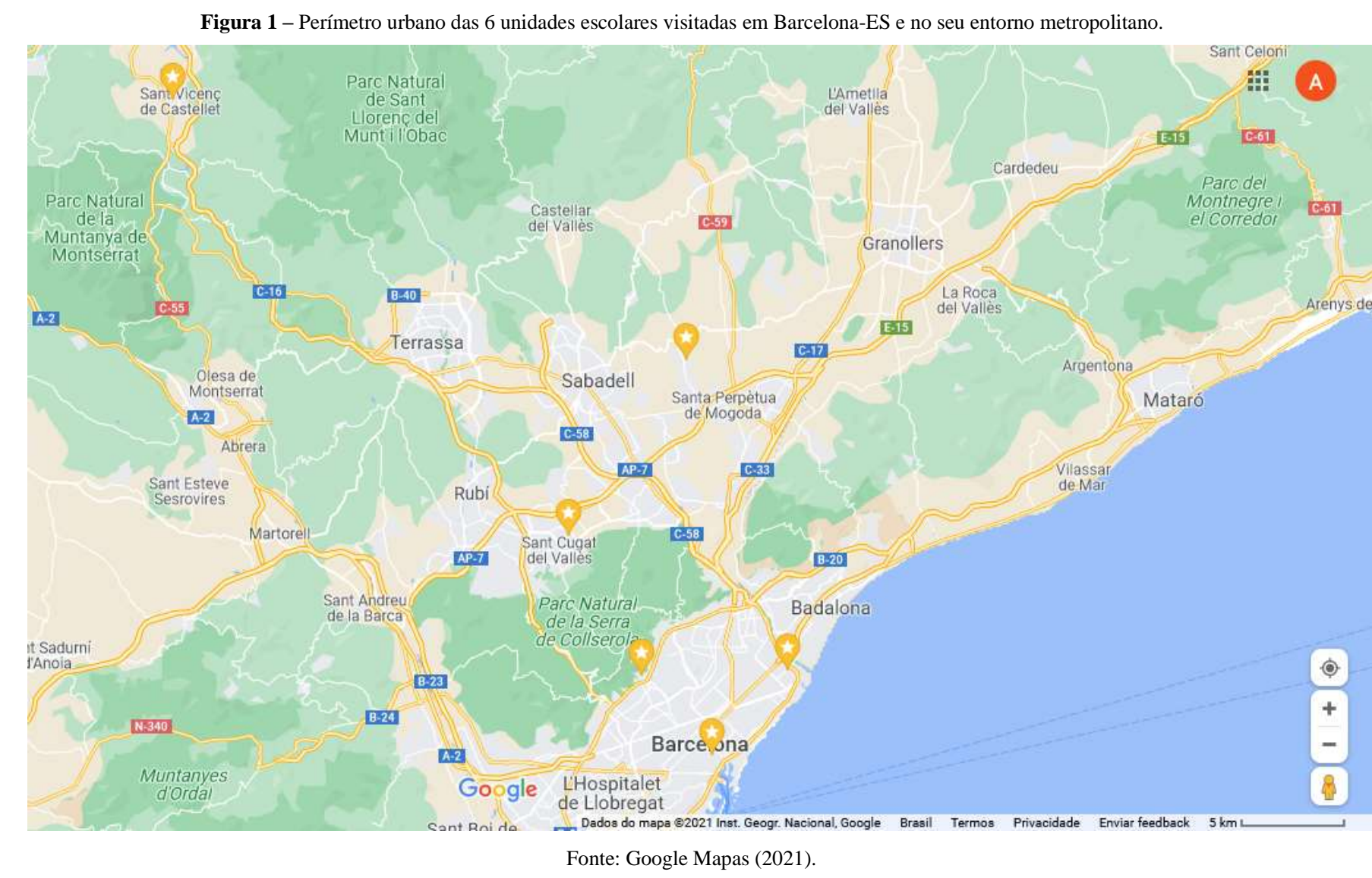

Para realizar as entrevistas com os professores, entramos em contato telefônico com as escolas de atuação de cada um deles. De posse destas informações (dias e horários de presença dos professores nas unidades escolares, bem como sua localização), montamos um calendário de visitas às escolas; entre os meses de abril e junho de 2017, realizamos as reuniões para apresentação da pesquisa e realização das entrevistas com os 9 professores, nas 6 escolas localizadas em distintas regiões do perímetro urbano da cidade de Barcelona-ES. Antes de iniciarmos as entrevistas, solicitamos aprovação para gravarmos suas narrativas.

Cumprida essa etapa, a estratégia de pesquisa concentrou-se nos processos de 1) transcrição literal do texto oral em escrito; 2) textualização, etapa na qual foram suprimidas as interferências da pesquisadora e foram traduzidas as narrativas do espanhol para o português; e 3) transcriação, que diz respeito ao momento no qual o pesquisador insere suas impressões e a atmosfera da entrevista (Leite, 2008, p. 73), no qual buscamos privilegiar a reflexão dos sujeitos e a manutenção do "sentido íntimo da entrevista” (Meihy, Holanda, 2007, p. 36), pois temi, assim como Guimarães (2011, p. 26), que demasiadas alterações pudessem fazer com que os professores não se reconhecessem no texto recriado.

Concluídos esses estágios, submetemos o texto final à apreciação e aprovação dos colaboradores entrevistados ao longo de todo o mês de junho de 2017, e somente após a análise e a aprovação do seu conteúdo por parte dos professorescolaboradores, o termo de consentimento autorizando o seu uso foi assinado. Importa salientar que, por questões éticas, decidimos pela alteração da identidade dos professores participantes, de modo que seus nomes foram todos substituídos.

\section{Resultados e Discussão}

O governo da Catalunha, através do seu Departamento de Educação, desenvolve, desde 2009, projetos de mediação de conflitos no contexto escolar; mapeados no Llibre Blanc de la Mediació a Catalunya (Casanovas, Magre \& Lauroba, 2010), primeiro documento que reuniu e sistematizou os princípios e o alcance da mediação em diversos âmbitos, incluindo o ensino 
médio, identificou um total de 253 institutos escolares que aderiram à proposta já no ano de seu lançamento, dentre os quais, 179 responderam a um questionário que permitiu compreender o objeto das mediações, em termos estatísticos; verificaram, por exemplo, que 52,25\% das mediações realizadas envolveu conflitos pontuais, sem violência; $22,67 \%$ estavam relacionadas a mal-entendidos e $16,88 \%$ a pequenas brigas. Outro dado que chamou atenção dos pesquisadores foi a alta participação dos estudantes atuando na condição de mediadores (69,32\% do total).

Defendendo a mediação como uma oportunidade de fazer com que os estudantes adquiram a habilidade e a competência de saber gerenciar conflito(s) de maneira positiva y democrática, o Departamento de Educação catalão parte do pressuposto de que para que isto ocorra, a mediação não deve incidir na infração à regra, ou no conflito em si, mas no modo como estas questões são abordadas e às deliberações que lhes são consequentes, envolvendo a intervenção de uma terceira pessoa, que, como vimos, pode ser outro estudante formado para tal (Generalitat de Catalunya, 2020). De todo modo, este órgão estabelece que as escolas são independentes para decidirem o modo como vão realizá-la, e para tanto, oferece um conjunto de formações e materiais didáticos para que a escola decida como e quando utilizar, levando em conta a sua especificidade local e o desejo dos estudantes.

Todavia, diferente do que ocorre nas escolas catalãs, o que se mostra notório no Brasil é que a aplicação de técnicas de mediação de conflitos ainda constitui um desafio pois, ao considerarmos a posição de quem fala (se diretores, professores ou alunos), é possível afirmar que a forma verticalizada com a qual muitas delas vêm sendo utilizadas entre nós produz relações caracterizadas pela assimetria e abrem espaço para que os conflitos se instaurem, sob a forma de "indisciplina, agressividade, revanchismo, apatia e problemas de relacionamento interpessoal" (Groppa Aquino, 2003, p. 378; Pereira, 2020).

No Brasil, a verticalização do tecido social, no qual as diferenças e assimetrias são convertidas em desigualdades que corroboram a prevalência da relação mando-obediência, são, segundo o entendimento de Chauí (2014), expressão da nossa trajetória política profundamente marcada pelo seu passado colonial escravocrata; por seu turno, afirma esta autora que tais circunstâncias engendraram: a constituição de uma esfera pública marcada por práticas políticas pautadas pelo patriarcalismo e clientelismo, resistência ao ideário preconizado pelos direitos humanos, a desqualificação do princípio formal da igualdade perante a Lei, a criminalização das lutas das organizações e movimentos sociais, a persistente discriminação sexual, étnica e de classe (Chauí, 2014, p. 257), caracterizando uma democracia de "baixa intensidade" ou "delegativa" (Sacavino, Candau, 2008, p. 77).

Por outro lado, as técnicas restaurativas de mediação de conflitos não podem ser desvinculadas da doutrina de proteção aos direitos humanos, pois defendem o princípio do respeito à dignidade do ser humano (Pereira, 2020) e também os valores da "cidadania democrática" (Schilling, 2014, p. 16), haja vista que sua consecução reivindica a "[...] constituição de prováveis sujeitos éticos, livres, dotados de palavra, racionais e sensíveis, com direito a ter direitos”. Consideramos, portanto, que o debate sobre a relação entre os direitos humanos e a mediação de conflitos pela via das práticas restaurativas possui um potencial emancipador ainda não devidamente realizado no contexto brasileiro. Neste sentido, afirmam Oxhorn e Slakmon (2005, p. 206) que

Em última análise, enquanto não se devem ver os mecanismos alternativos de justiça, a exemplo da justiça restaurativa, como panaceias para solucionar todos os déficits democráticos do Brasil, eles de fato oferecem o potencial para prover uma base muito firme para esforços subsequentes. Não apenas eles oferecem a possibilidade de fortalecer a base dos direitos de cidadania e democracia - direitos civis - eles o fazem de modo que podem começar a empoderar a sociedade civil e proporcionar a grupos em desvantagem as habilidades e senso de eficácia requeridos para que eles empurrem suas próprias agências mais adiante em direção a avançar em seus direitos de cidadania e na qualidade da democracia brasileira. Um círculo vicioso de crime, violência e sistemas de justiça sem legitimidade pode ser transformado, em última instância, em uma democracia mais ampla, mais inclusiva. 
De acordo com Jaccoud (2005, p. 163, 164), a justiça restaurativa emerge das tradições indígenas da América do Norte e do Sul, do Canadá, de algumas etnias da África e dos aborígenes da Nova Zelândia, cuja organização social priorizava práticas orientadas a uma rápida resolução dos conflitos com vistas à recomposição da estabilidade social interrompida. E foi a partir das experiências realizadas na Nova Zelândia, nas quais foi utilizada com o objetivo de diminuir o expressivo aumento de detenções da juventude Maori que a justiça restaurativa foi popularizada, tendo sido introduzida em uma grande escola da Austrália, em 1994. Doravante, a justiça restaurativa propagar-se-ia em diversas escolas pelo mundo tendo em vista o arrefecimento das múltiplas formas de manifestação da violência neste espaço (Morrison, 2005, p. 295). Assim, no âmbito educacional, essa abordagem tem sido geralmente utilizada para prevenção da violência e das situações de conflito nas escolas desde a perspectiva dialógica, cujas condutas devem ser orientadas ao entendimento.

Em âmbito internacional, a Justiça Restaurativa encontra respaldo na Resolução 2002/12 ${ }^{11}$, da ONU, intitulada "Princípios Básicos para o Uso de Programas de Justiça Restaurativa em Matéria Penal", que trata das ações relativas à justiça restaurativa no sistema criminal; neste documento, o processo restaurativo é compreendido como qualquer técnica que propicie ao agressor e à vítima protagonizarem a solução do litígio em questão, geralmente com o auxílio de um facilitador. Este processo pode abranger as etapas de mediação, conciliação, reunião familiar ou comunitária e círculos restaurativos ${ }^{12}$ (ONU, 2016).

Em âmbito nacional, os modelos restaurativos para resolução de conflitos passam a ser objeto de interesse dos magistrados em 2003, pois além de serem uma recomendação da ONU, as experiências empreendidas e incorporadas por outros Países davam mostras de que poderiam constituir-se como uma possibilidade ao sistema de justiça criminal. De modo que, em 2005, iniciam a execução da proposta intitulada "Promovendo Práticas Restaurativas no Sistema de Justiça Brasileiro", resultado de uma parceria entre o Ministério da Justiça e o Programa das Nações Unidas para o Desenvolvimento (PNUD), que consistiu no financiamento de três projetos de Justiça Restaurativa em caráter piloto nos municípios de Porto Alegre (RS), São Caetano do Sul (SP) e Brasília (DF) (Slakmon, Vitto \& Pinto, 2005, p. 11; Melo, Ednir \& Yasbek, 2008, p. 12).

Em São Caetano do Sul (SP), a Vara da Infância e da Juventude executou o projeto "Justiça e Educação: parceria para a cidadania", e dado o êxito desta parceria, até então inédita no Brasil, a experiência foi expandida para o município de Guarulhos (SP) e para o bairro de Heliópolis, em São Paulo (SP), que a realizaram, em 2006, sob o título "Justiça e Educação em Heliópolis e Guarulhos: parceria para a cidadania", reeditando a cooperação entre o Tribunal Estadual de Justiça e a Secretaria Estadual de Educação (Ednir, 2007, p. 17).

A justiça restaurativa chegaria no ano seguinte em Campinas (SP), por meio da colaboração entre o Tribunal Estadual de Justiça, o Conselho Municipal dos Direitos da Criança e do Adolescente (CMDCA) e as Secretarias Estadual (SEE-SP) e Municipal de Educação (SME-SP). No entanto, conforme nos informa Quintana (2010, p. 29, 30), o processo piloto iniciado em 2007 e intitulado "Justiça e Educação - Novas Perspectivas", não recebeu nenhum tipo de diretriz quanto à sua implementação, tendo sido inspirado nas atividades que a precederam (em âmbito nacional e estadual), e respaldado na Resolução do Conselho Econômico e Social das Nações Unidas da ONU, na Declaração de Viena (1993) e na Lei de Juizados Especiais $\mathrm{n}^{\circ} 11.313^{13}$, que dispõe sobre os processos conciliatórios para as infrações penais de menor potencial ofensivo (art. $60)$.

\footnotetext{
${ }^{11}$ Recuperado de: http://www.justica21.org.br/j21.php?id=366\&pg=0\#.V7U0ZfkrLIV

${ }^{12}$ A mediação pode ser direta, contando com a presença dos sujeitos e seus respectivos apoios; ou indireta, sem vítima ou infrator presentes. Os círculos restaurativos constituem-se enquanto um espaço no qual os sujeitos diretamente afetados, bem como a comunidade ou quaisquer outros interessados na resolução do conflito, reúnem-se para debater a questão e juntos encontrarem sua solução; sua metodologia prevê o direito a fala de cada um dos participantes a partir de algumas regras previamente acordadas, tendo em vista a melhoria dos relacionamentos e dos vínculos comunitários. Segundo Scuro Neto (2008, p. 8), "Tal variedade é traço marcante da Justiça Restaurativa, que 'funciona diferentemente para diferentes tipos de pessoas [...].".

${ }^{13}$ Recuperado de: http://www.planalto.gov.br/ccivil_03/_Ato2004-2006/2006/Lei/L11313.htm
} 
O curso de formação continuada "Cultura Restaurativa e Suas Práticas", foi realizado em Campinas-SP, através de uma parceria entre a Secretaria de Educação do Estado de São Paulo (SEE-SP), a Vara da Infância e Juventude de Campinas (Tribunal de Justiça - TJ/SP) e a Federação das Entidades Assistenciais de Campinas (FEAC). Destinado aos professores e gestores da rede pública estadual de educação, seu objetivo foi o de promover a cultura da não violência no âmbito das escolas públicas do supramencionado município; para tanto, estabeleceu como objetivos específicos: desenvolver habilidades da comunicação não violenta; e qualificar gestores e professores para realizar práticas restaurativas em suas unidades de ensino. A história oral de vida dos professores egressos desse curso constituiu o objeto do doutorado. De modo que as percepções apresentadas tem como base a história de vida dos professores, a partir de suas narrativas, de suas experiências e das relações interpessoais que estabeleceram com os direitos humanos e com a justiça no decorrer de suas vidas, dentro e fora das salas de aula.

Entre os professores houve consenso em considerar a justiça restaurativa importante, ainda que nem sempre "restaurem" as relações, acreditam que sua realização deva ser feita na perspectiva de um trabalho contínuo. O principal ganho atribuído à formação "Cultura restaurativa e suas práticas" foi a introdução do diálogo em suas práticas pedagógicas, embora um quantitativo expressivo informe que já possuía uma predisposição natural à escuta e que a sua participação no curso apenas os municiou com as técnicas adequadas para mediar os conflitos.

Apareceu com alguma frequência na narrativa dos professores a insurgência às regras estabelecidas na escola e os conflitos daí decorrentes: houve um conjunto significativo de professores que defenderam sua existência na escola, mas não mencionaram em momento algum que sua construção deveria ser feita pelo coletivo escolar. Em consonância com Dubet (1997), advogamos que a escola deve repensar o trabalho educativo a partir da instauração de uma democracia escolar, ou seja, que as regras da vida coletiva que aí se estabelecem sejam definidas e aplicadas, mas que sejam elaboradas conjuntamente.

Claro está que as normas orientam o funcionamento e manutenção da ordem escolar e consideramos sua existência importante, mas consideramos que sua criação deveria ser feita de modo colaborativo e democrático, envolvendo professores, alunos, gestores e demais membros do coletivo escolar. Contudo, o que se observa nas escolas é geralmente a definição unilateral das regras e normas, impostas, sem debate, regras que proíbem o uso de determinados acessórios pelos alunos, os bonés, por exemplo, sem levar em conta que esses representam uma forma de expressão juvenil (Abramovay, Castro, Silva \& Cerqueira, 2016, p. 8, 9); ou seja, seria importante alguma reciprocidade no estabelecimento das regras, que sua elaboração envolvesse a todos, para que pudesse ser considerada justa (Dubet, 1997).

Em menores percentuais, apresentaram percepções favoráveis aos direitos humanos: em âmbito escolar, atribuíram sua ausência à formação técnica e despolitizada dos professores; na sociedade, associaram as violações a esses direitos ao desconhecimento e à falta de educação política. Desconhecimento que também notamos nas expressões de alguns professores, quando não o absoluto silêncio com relação a essa temática, que não remetem à tipologia dos silêncios concebida por Orlandi ${ }^{14}$ (2007), mas à dificuldade em atribuir sentido a algo com o qual não têm contato e que por essa razão, nunca foi objeto de reflexão. Essa ausência encontra respaldo nos dados já apresentados sobre a percepção dos brasileiros acerca dos direitos humanos e o [...] o desprestígio justamente daqueles direitos que deveriam garantir a possibilidade de os sujeitos intervirem ativamente na esfera pública e nos conflitos sociais, de classe etc., em que estão (queiram ou não) envolvidos. (Kehl, 2010, p. $35)$.

\footnotetext{
${ }^{14} \mathrm{O}$ silêncio fundador é por esta autora definido como “[...] aquele que existe nas palavras, que significa o não-dito e que dá espaço de recuo significante, produzindo as condições para significar." (Orlandi, 2007, p. 24); a política do silêncio é dividida entre silêncio constitutivo e silenciamento, sendo que o primeiro refere-se ao silêncio sofrido em situação de censura, e o último trata do silêncio como resistência, no qual analisa as estratégias utilizadas por vozes sociais, que, reprimidas pela ideologia dominante, buscam significar em silêncio. De acordo com a concepção de Orlandi (2007), todos esses tipos de silêncio são carregados de sentidos.
} 
Embora tenha havido consenso sobre os benefícios da justiça restaurativa neste lócus, sobretudo, no que diz respeito à introdução do diálogo, a grande maioria identifica ser este um trabalho realizado solitariamente, ou porque falta tempo e espaço para envolver todo o coletivo escolar na proposta, ou porque não há interesse por parte do coletivo em se envolver; no entanto, o que se pode verificar nas narrativas dos professores é que as práticas restauradoras ou se dão em contextos marcados por relações de poder e autoritarismos, ou são por elas atravessadas. Práticas que até solucionam os conflitos, mas não empoderam os sujeitos, tampouco os preparam para o agonismo de posições da esfera pública; sendo exercidas com base nos dispositivos de controle, retroalimentam neste lócus a mesma violência que pretendem arrefecer. Mas como promover deslocamentos nessa direção? Como exemplo de experiência bem-sucedida em mediação de conflitos, destacamos a experiência desenvolvida em Barcelona-ES.

\section{Percepção dos professores sobre conflito e mediação no contexto escolar da Catalunha}

A compreensão expressa pelo Departamento de Educação da Catalunha em diversos documentos e normativas é de que o conflito é indissociável da vida do ser humano em seu processo de socialização. A luta pela obtenção de recursos, a interação com os outros ou a própria auto aceitação significam enfrentar situações de conflito nas quais é preciso aprender a administrar, até porque não é realista pensar que o conflito possa ser evitado.

Do contexto psicológico, sociológico, filosófico, político... o conflito está associado ao confronto entre duas posições muito difíceis de conciliar. Frequentemente, existem objetivos, necessidades e interesses conflitantes que geram problemas emocionais, insegurança, incerteza, mal-entendidos e falta de comunicação que tornam difícil raciocinar sobre os próprios desejos e compreender os desejos dos outros para compartilhar significados.

Do contexto educacional, as múltiplas situações que se vivenciam nas escolas e nas salas de aula, geram em alguns casos incômodos como as diferentes circunstâncias vividas pelos professores na sua prática diária ou entre professores e alunos, ou na relação entre a escola e as famílias, entre outras, que é preciso revelar e gerenciar por meio da comunicação e do diálogo. Trata-se de criar uma cultura compartilhada que leve em conta o bem comum e que, por sua vez, também satisfaça os desejos individuais

A escola sempre foi sensível às situações de conflito, de modo que quando isso se tornou evidente, buscou formas de restabelecer a convivência entre os grupos adversários. A princípio, a solução foi educar em valores que ajudassem na resolução de conflitos. Considerou-se que em todos os conflitos existiam posições duais ou bipolares e que deviam ser resolvidas através de regulamentos claros, elaborados verticalmente e que resultavam na existência de vencedores e vencidos numa perspectiva de pensamento punitivo. Os sucessos no restabelecimento da convivência, desse ponto de vista, foram muito escassos, pois implicou em julgamento punitivo para um dos grupos adversários.

Em 1996, o relatório Delors ${ }^{15}$ estabeleceu que um dos desafios educacionais do século XXI era aprender a conviver e que esse aprendizado deveria ser realizado ao longo da vida. Isso implicou uma mudança de paradigma na hora de intervir e resolver os conflitos que surgiram no sentido de que não podiam ser resolvidos por meio de julgamentos sobre os atores ou grupos envolvidos, mas sim que todos deveriam entender a natureza do conflito. Para isso, foi fundamental passar do regulamento sancionador à mediação, ou seja, da verticalidade das decisões ou julgamentos para a horizontalidade que considera os grupos opostos como simétricos e que só poderão resolver seus antagonismos e chegar a acordos satisfatórios para ambas as partes partindo do raciocínio e do diálogo. A mediação foi entendida como uma nova estratégia na gestão positiva dos conflitos que melhorou as relações e o clima escolar, promovendo mudanças para que cada pessoa possa enfrentar os conflitos tanto presentes como no futuro e que sejam parte da solução. Promove o empoderamento pessoal para o enfrentamento de conflitos modificando a realidade a partir da gestão democrática da convivência.

\footnotetext{
${ }^{15}$ UNESCO (1996). Educació: hi ha un tresor amagat a dins. Centre UNESCO de Catalunya.
} 
A implementação da mediação no âmbito das escolas na Catalunha teve início nos anos $90^{16}$ e foi finalizada com um primeiro regulamento no ano letivo $2006-2007^{17}$ com o objetivo de orientar uma nova forma de resolução de conflitos e ensinar os jovens a viverem juntos. Propôs-se que em situações de confronto entre grupos, sejam transmitidos elementos de reflexão para que por si mesmos possam chegar a um acordo satisfatório para ambas as partes, criando assim uma cultura de convivência comum para reconstruir relações sociais deterioradas. As regulamentações iniciais excluíam da mediação situações de agressão física, comportamento humilhante ou ameaças, bem como aquelas relacionadas a gênero, sexualidade, racismo ou xenofobia.

Um aspecto a destacar é a inclusão da figura do mediador, ou seja, uma terceira pessoa com formação específica para auxiliar na resolução do conflito. O mediador deve gerir a evolução do processo, que a discussão seja de igual para igual e que as soluções alcançadas sejam justas e equitativas. Para tanto, é necessário que o mediador assuma, entre outros, os seguintes princípios: tranquilidade, empatia, neutralidade e sigilo para enfrentar as situações que surgirem.

Os regulamentos iniciais sofreram diferentes mudanças nos anos subsequentes. Recentemente foi complementado com o Projecte de Convivència i èxit educatiu ${ }^{18}$, de setembro de 2020 , que estabelece que a finalidade é ensinar e aprender a viver e conviver, entendendo que não se trata de uma simples convivência com os outros, mas da relação entre as pessoas a partir de redes de senso comum compartilhado e baseadas em valores como pluralidade, participação democrática, inclusão social, igualdade de oportunidades, respeito pela diferença, gestão positiva de conflitos e uma cultura de paz. Isso implica a aceitação dos outros em um sentido de pertença e contribuição pessoal na sociedade. Cada centro educativo, tendo em conta a sua casuística própria, deve especificar as ações a realizar a partir das salas de aula, do centro e do entorno para obter um clima escolar ótimo que permita contribuir para o sucesso pessoal, acadêmico, social e profissional de todos os alunos. Nesse sentido, afirmam Carrasco Pons, Villà Taberner e Ponferrada Arteaga (2016) que

O sistema educacional (do $\operatorname{LOGSE}^{19}$ ao $\operatorname{LOE}^{20}$ ) estabelece a distinção entre a missão de educar em atitudes, valores e normas e em conteúdos e procedimentos por parte do corpo docente. Ou seja, idealmente, o professor pode ser considerado um especialista (em conteúdos e valores) e uma referência (em atitudes, valores e normas) e, nesse sentido, a educação para a resolução de conflitos por meio da mediação representaria um avanço democrático que incluiria ambos os aspectos e seria esperado que o corpo docente pudesse liderar como parte de sua missão. Mas a filosofia a partir da qual a mediação é promovida no ambiente escolar não pode ser apenas ou principalmente uma questão de aprendizagem para os alunos, na medida em que tem implicações para a transformação de toda a cultura escolar tradicional e de suas respostas aos conflitos. Assim, a função educativa dos processos de mediação também deve afetar os adultos da instituição escolar. (Pons, Tarbener \& Arteaga, 2016, p. 127, tradução nossa).

Por essa razão Carrasco Pons, Villà Taberner e Ponferrada Arteaga (2016) consideram ser necessário acrescentar à mediação em âmbito escolar a questão cultural; e uma vez que pretende promover o respeito à alteridade e a revisão das normas e regras estabelecidas com vistas à socialização de uma cultura não-violenta no contexto educacional, a mediação demanda orientação pedagógica específica, pois a resolução do conflito deve ser mediada pelo diálogo e por meio dela buscase o entendimento (consenso), permitindo aos envolvidos se posicionarem face ao conflito instaurado e refletirem sobre as consequências daí resultantes. É o que verificamos na entrevista do professor J.:

\footnotetext{
${ }^{16}$ As primeiras experiências de mediação ocorreram em 1994, na Comunidad Autónoma del País Vasco, com o objetivo de buscar soluções para a convivência que permitiriam superar o conflito político no qual se vivia desde os anos 70 .

${ }^{17}$ Decret 279/2006, de 4 de juliol, sobre derechos y deberes del alumnado y regulación de la convivència en los centros educativos no universitarios de Catalunya. Diari Oficial de la Generalitat de Catalunya, núm. 4670, de 6 de juliol de 2006.

${ }^{18}$ Departament d'Educació (2020). Projecte de Convivència i èxit educatiu. Generalitat de Catalunya.

${ }^{19}$ Ley Orgánica General del Sistema Educativo (LOGSE), de 3 de octubre de 1990. https://www.boe.es/buscar/doc.php?id=BOE-A-1990-24172

${ }^{20}$ Ley Orgánica 2/2006, de 3 de mayo, de Educación. https://www.boe.es/diario_boe/txt.php?id=BOE-A-2006-7899
} 
Havia muito conflito na escola, então decidimos fazer um plano de mediação, eu me voluntariei a fazer a formação pela Generalitat, em 1999, e passamos a estimular que os estudantes também participassem dessas formações, de modo que as questões envolvendo brigas, bullying, etc., foram assumindo um outro grau de importância quando os próprios estudantes converteram-se em mediadores e passaram a incumbir-se da mediação de conflitos com seus pares.

Como mencionado, na região da Catalunha a mediação escolar é realizada como uma estratégia para resolução de situações de conflitos entre iguais, de modo que a maior parte dos mediadores são também alunos, com o apoio e supervisão de um membro do corpo docente, tarefa geralmente atribuída aos professores responsáveis pelas comissões de mediação dos centros escolares. Em havendo situações de conflito entre professores e alunos, o professor deve aceitar dialogar em condição de igualdade com os estudantes. Ainda de acordo com Carrasco Pons, Villà Taberner e Ponferrada Arteaga (2016), há consenso na comunidade escolar da Catalunha sobre os impactos positivos dos processos de mediação, ainda que essas percepções convivam, em meio escolar, com símbolos da autoridade e da disciplina que terminam por influenciar o modo como tem sido realizada; podemos encontrar essa percepção na fala da professora S., quando afirma que

Antes havia a comissão de mediação que se reunia uma vez a cada três meses, mas essa periodicidade comprometia a resolução do conflito e víamos a repetição dos casos, sendo tratados como uma questão disciplinar, quase sempre envolvendo os mesmos atores. Quando a comissão de convivência passou a se reunir semanalmente e a envolver pais de alunos, professores, alunos, e a estimular a formação de alunos para realização da mediação entre iguais, vimos desaparecer aquela repetição. Claro que há um ou outro caso mais complexo, que demanda um acompanhamento da coordenação de convivência, mas eles hoje são muito pontuais. (S., 2017, informação verbal, tradução nossa).

De acordo com o Llibre Blanc de la Mediació a Catalunya (Casanovas, Magre \& Lauroba, 2010), o Departamento de Educação realiza formações de 40 horas para as escolas de ensino médio catalãs que desejam integrar o programa de mediação de conflitos, além de produzir materiais didáticos disponibilizados online gratuitamente. Também são muitos os centros que oferecem formação para os professores, que são os responsáveis pela coordenação das atividades nas escolas, e também para os próprios alunos. O funcionamento da mediação ocorre do seguinte modo:

A Generalitat começou formando os professores e depois formou os alunos. Nos centros escolares sempre tem uma pessoa, geralmente um psicopedagogo, que se encarrega da coordenação da equipe de mediadores da escola. Essa equipe é constituída por um grupo de alunos, o quantitativo depende do tamanho da escola, e de um professor. Então quando se detecta a necessidade de mediação, os estudantes são acionados e são eles que assumem sua realização. $O$ professor não intervém em momento algum, a menos que seja acionado pelos estudantes. A mediação entre os alunos é feita exclusivamente pelos alunos. (M., 2017, informação verbal, tradução nossa).

Entretanto, ainda segundo o Llibre Blanc de la Mediació a Catalunya (Casanovas, Magre \& Lauroba, 2010), há bastante ênfase na formação dos professores e dos estudantes, mas a formação das famílias e do coletivo escolar (gestores, funcionários, e outros) ainda é bastante escassa, e quando ocorre, é realizada pelo Departamento de Educação, haja vista que poucas escolas assumem seu oferecimento, e quando o fazem, são poucos os sujeitos que dela participam, apesar de ser um dos públicos mais numerosos e, eventualmente, coprotagonistas dos conflitos que ocorrem na escola.

Destacamos que os princípios que orientam a formação para mediação de conflitos nas escolas catalãs são: a voluntariedade da participação, a imparcialidade da pessoa mediadora e a confidencialidade de todo o processo. O objetivo é a promoção da resolução dialogada dos conflitos, prioritariamente, entre iguais, e para que o consenso entre as partes envolvidas seja atingido, é considerada de suma importância a escolha cuidadosa da técnica de mediação que será utilizada, assim como a observância às condições que devem ser garantidas à sua realização. 


\section{Considerações Finais}

As primeiras experiências de mediação escolar na região da Catalunha começam na década de 90, como uma iniciativa de professores que haviam recebido esta formação específica. Mas é a partir de 2009 que o governo estabelece a obrigatoriedade de introduzir a mediação em todos institutos educativos da Catalunha, liderando, na Espanha, um papel protagônico na defesa e uso da mediação de conflitos no contexto escolar (Viana-Orta, 2019).

A ênfase atribuída ao processo educativo para a construção de uma cultura pautada pela pluralidade de ideias, pela participação democrática, justiça social, igualdade de oportunidades, respeito pela diferença, gestão positiva de conflitos e uma cultura dos direitos humanos, sobretudo, do ponto de vista normativo, não é casual: sendo a escola um espaço formativo, desempenha um papel fundamental para ensejar uma revisão dos valores e das práticas sociais. O que a pesquisa realizada no Brasil e na Espanha evidenciou é que as relações sociais na escola podem reproduzir autoritarismos e atitudes segregatórias e excludentes, mas é inegável que a instituição escolar se constitui como um espaço privilegiado para a ruptura com essas práticas (Pereira, 2020).

As técnicas de mediação de conflitos em ambos os países evidenciam que as práticas específicas nas quais elas se inscrevem e o tipo de subjetividades que forma, na medida em que busca promover o respeito à alteridade, o protagonismo, a emancipação e a reflexão dos indivíduos, especialmente, quando ocorrem no espaço concreto e heterogêneo que é a escola, contém um profundo teor formativo e, por meio do diálogo, podem potencializar a construção de uma cultura da não-violência, dos direitos humanos, da inclusão social e o arrefecimento da violência e das situações de conflito no contexto educacional.

Verificamos na narrativa de um percentual significativo de professores brasileiros, que ao invés do estabelecimento de relações igualitárias, as técnicas de mediação de conflitos são conduzidas em meio escolar ocultando um outro tipo de assimetria: dependendo da posição de quem fala (se diretores, professores ou alunos), terminam por suprimir o diálogo, anulando o protagonismo dos sujeitos por meio da coerção, em suma: reproduzem a mesma violência que pretendem prevenir. E este é o contexto no qual as técnicas de mediação de conflitos devem ser instauradas; o que os professores observaram é que na prática escolar, apesar de convincentemente detalhadas, essas propostas não são efetivamente concretizadas pois os valores que lhe são concernentes, em geral, não são vivenciados.

Por outro lado, foi possível identificar na narrativa dos professores catalães entrevistados, e isso também está previsto na legislação educacional consultada, que para a realização da mediação escolar todos: gestores, professores e alunos, devem passar por uma formação nas técnicas de mediação de conflitos, mas sua realização tem, necessariamente, que ser horizontal; para que isso ocorra, há uma compreensão tácita de que o protagonismo na condução da mediação deve ser assumido pelos alunos: em cada sala de aula existem os alunos responsáveis pela mediação, assim, quando há necessidade, os envolvidos os buscam para que eles assumam a mediação, ou seja, os conflitos que acontecem entre os alunos, são por eles mesmos solucionados pela mediação, sem envolver professores ou gestores; esses apenas acompanham a situação, ou nela intervém, se são demandados pelos alunos, ou quando verificam que uma determinada situação é mais grave ou delicada.

Assim, não obstante as diferenças entre as culturas brasileira e espanhola, o uso das técnicas restaurativas estão sendo colocadas em prática há algum tempo no território espanhol, o que nos permite compreender os limites, as possibilidades e os desafios relativos à sua execução, ao tempo em que contribuem para pensar outras possibilidades para a formulação de ações que favoreçam sua implementação na realidade brasileira.

Colocamos como resultado uma discussão, em forma de artigo, que desse conta do percurso percorrido na instância da pesquisa realizada. Com isso não queremos dizer que o assunto se esgota aí, pelo contrário, acreditamos que exemplos assim ensejam a abertura de questões e, consequentemente, a construção de trabalhos que permitam pensar como a proposta da justiça restaurativa pode se dar em outros termos entre nós. 


\section{Agradecimentos}

Agradeço à Coordenação de Aperfeiçoamento de Pessoal de Nível Superior (CAPES) pela concessão da bolsa de doutorado-sanduíche que permitiu a realização desta pesquisa junto à Universitat Autónoma de Barcelona (UAB), em 2017.

\section{Referências}

Abramovay, M., Castro, M. G., Silva, A. P. \& Cerqueira, L. (2016). Diagnóstico participativo das violências nas escolas: falam os jovens. FLACSO - Brasil, OEI, MEC.

Bolivar, A. Justicia social y equidad escolar: una revisión actual. (2012). Revista Internacional de Educación Para La Justicia Social. 1(1), 9-45. http://www.rinace.net/riejs/numeros/vol1-num1/art1.pdf

Carrasco Pons, S., Villà Taberner, R., \& Ponferrada Arteaga, M. Resistencias institucionales ante la mediación escolar: una exploración en los escenarios de conflicto. Revista De Antropología Social, 25(1), 111-131. https://doi.org/10.5209/rev_RASO.2016.v25.n1.52627

Casanovas, P.; Magre, J.; Lauroba, E. (Orgs.) (2010). Llibre Blanc de la Mediació a Catalunya. Barcelona: Generalitat de Catalunya, Departament de Justícia. http://www.llibreblancmediacio.com/

Chauí, M. (2014). Manifestações ideológicas do autoritarismo brasileiro. (2 ed.) Autêntica Editora; Editora Fundação Perseu Abramo.

Decret 279, de 4 de juliol de 2006 (2006, 4 juliol). Sobre derechos y deberes del alumnado y regulación de la convivència en los centros educativos no universitarios de Catalunya. Diari Oficial de la Generalitat de Catalunya, núm. 4670, de 6 de juliol de 2006.

Dubet, F. O que é uma escola justa? (2004). Cadernos de Pesquisa, 34(123), 539-555. Recuperado de: http://www.scielo.br/pdf/cp/v34n123/a02v34123.pdf

Dubet, F. A escola e a exclusão. (2003). Cadernos de Pesquisa, (119), 29-45. Recuperado de: http://www.scielo.br/pdf/cp/n119/n119a02.pdf

Dubet, F. Quando o sociólogo quer saber o que é ser professor. (1997). Revista Brasileira de Educação, (5), 222-231. http://anped.tempsite.ws/novo_portal/rbe/rbedigital/RBDE05_6/RBDE05_6_19_ANGELINA_E_MARILIA.pdf

DW. (2019, 26 de abril). Brasil lidera ranking da OCDE de violência contra professores. Folha de São Paulo. https://www1.folha.uol.com.br/educacao/2019/04/brasil-lidera-ranking-da-ocde-de-violencia-contra-professores.shtml

Ednir, M. (2007). Justiça e educação em Heliópolis e Guarulhos: parceria para a cidadania. CECIP. http://www.mpsp.mp.br/portal/page/portal/Cartilhas/justica-e-educacao_web.pdf

Generalitat de Catalunya. (2020). Projecte de educatiu. http://xtec.gencat.cat/web/.content/centres/projeducatiu/convivencia/documents/PdC.pdf

Groppa Aquino, J. (2003). Disciplina e Indisciplina como representações na educação contemporânea. In R. L. L. Barbosa (Org.). Formação de Educadores: desafios e perspectivas (pp. 377-385). Editora UNESP.

Guimarães, A. M. (2011). Vidas de Jovens Militantes. [Tese de Livre Docência, Universidade Estadual de Campinas]. http://www.fe.unicamp.br/servicos/centro_memoria/publicacoes.htm

Instituto de Pesquisa Econômica Aplicada [IPEA]. (2019). Atlas da Violência. https://www.ipea.gov.br/atlasviolencia/download/19/atlas-da-violencia-2019

Instituto de Pesquisa Econômica Aplicada [IPEA]. (2017). Atlas da Violência. http://www.ipea.gov.br/portal/images/170602_atlas_da_violencia_2017.pdf

Instituto Nacional de Estudos e Pesquisas Educacionais Anísio Teixeira. (2019) Relatório nacional: pesquisa internacional sobre ensino e aprendizagem: Talis. https://www.gov.br/inep/pt-br/assuntos/noticias/institucional/bullying-e-violencia-desafios-nas-escolas-brasileiras

Kehl, M. R. (2010). Direitos humanos: a melhor tradição da modernidade. In G. Venturi (Org.), Direitos humanos: percepções da opinião pública (pp. 33-41). http://www.biblioteca.presidencia.gov.br/publicacoes-oficiais/catalogo/lula/direitos-humanos-percepcoes-da-opniao-publica-2010/view

Jaccoud, M. (2005). Princípios, Tendências e Procedimentos que Cercam a Justiça Restaurativa. In C. Slakmon, R. C. P. Vitto \& R. S. G. Pinto (Orgs.). Justiça Restaurativa (pp. 163-188). Ministério da Justiça; Programa das Nações Unidas para o Desenvolvimento [PNUD]. https://www.ufpe.br/ppgdh/images/documentos/jrestaurativa.pdf

Lei $n^{\circ} 11.313$, de 28 de junho de 2006 (2006, 28 junho). Altera os arts. 60 e 61 da Lei $n^{o} 9.099$, de 26 de setembro de 1995 , e o art. $2^{\circ}$ da Lei $n^{\circ} 10.259$, de 12 de julho de 2001, pertinentes à competência dos Juizados Especiais Criminais, no âmbito da Justiça Estadual e da Justiça Federal. http://www.planalto.gov.br/ccivil_03/_Ato2004-2006/2006/Lei/L11313.htm

Leite, T. A. (2008). O dilema da interferência na História Oral: novos problemas e novas respostas. Revista de História Oral, 2(3), 65-82. https://diversitas.fflch.usp.br/sites/diversitas.fflch.usp.br/files/2019-09/Oralidades\%203.pdf

Ley Orgánica 1/1990, de 3 de octubre (1990), de Ordenación General del Sistema Educativo. https://www.boe.es/buscar/doc.php?id=BOE-A-1990-24172

Ley Orgánica 2/2006, de 3 de mayo (2006), de Educación. https://www.boe.es/diario_boe/txt.php?id=BOE-A-2006-7899

Meihy, J. C. S. B.\& Holanda, F. (2007). História oral: como fazer, como pensar. Contexto. 
Melo, E. R., Ednir, M. \& Yasbek, V. C. (2008). Justiça Restaurativa e Comunitária em São Caetano do Sul: aprendendo com os conflitos a respeitar direitos $e$ promover cidadania. CECIP. http://www.tjsp.jus.br/Download/CoordenadoriaInfanciaJuventude/JusticaRestaurativa/SaoCaetanoSul/Publicacoes/jr_saocaetano_090209_bx.pdf

Ministério da Educação [MEC]. (2018). Base Nacional Comum Curricular. http://basenacionalcomum.mec.gov.br/

Morrison, B. (2005). Justiça Restaurativa nas Escolas. In C. Slakmon, R. C. P. Vitto \& R. S. G. Pinto (Orgs.). Justiça Restaurativa (pp. 297-322). Ministério da Justiça; Programa das Nações Unidas para o Desenvolvimento [PNUD]. https://www.ufpe.br/ppgdh/images/documentos/jrestaurativa.pdf

Organização das Nações Unidas [ONU]. (1948). Declaração Universal dos Direitos Humanos [DUDH]. http://www.oas.org/dil/port/1948\%20Declara\%C3\%A7\%C3\%A3o\%20Universal\%20dos\%20Direitos\%20Humanos.pdf

Organização das Nações Unidas [ONU]. (1993). Declaração e Programa de Ação de Viena. http://www.oas.org/dil/port/1993\%20Declara\%C3\%A7\%C3\%A3o\%20e\%20Programa\%20de\%20Ac\%C3\%A7\%C3\%A3o\%20adoptado\%20pela\%20Confer\% C3\%AAncia\%20Mundial\%20de\%20Viena\%20sobre\%20Direitos\%20Humanos\%20em\%20junho\%20de\%201993.pdf

Organización de las Naciones Unidades para la Educcación, la Ciencia y la Cultura [UNESCO]. (1996). Educació: hi ha un tresor amagat a dins. Centre UNESCO de Catalunya: 1996. https://www.escolanova21.cat/wp/wp-content/uploads/2019/11/UNESCO-Educacio_-hi-ha-un-tresor-amagat-a-dins.pdf

Orlandi, E. P. (2007). As formas do silêncio: no movimento dos sentidos. (6a ed.). Editora da Unicamp.

Oxhorn, P. \& Slakmon, C. (2005). Micro-justiça, desigualdade e cidadania democrática: a construção da sociedade civil através da justiça restaurativa no Brasil. In C. Slakmon, R. C. P. Vitto \& R. S. G. Pinto (Orgs.). Justiça Restaurativa (pp. 189-212). Ministério da Justiça, Programa das Nações Unidas para o Desenvolvimento [PNUD]. https://www.ufpe.br/ppgdh/images/documentos/jrestaurativa.pdf

Paixão, M. (2019, 15 outubro). A cada dia, mais de 100 professores são afastados por transtornos mentais em São Paulo. Brasil de Fato. https://www.brasildefato.com.br/especiais/a-cada-dia-mais-de-100-professores-sao-afastados-por-transtornos-mentais-em-sp

PEREIRA, A. C. R. (2020). Direitos humanos, justiça restaurativa e violência escolar. Paco Editorial.

PINHO, A. \& MARIANI, D. (2017, 17 setembro). SP tem quase 2 professores agredidos ao dia; ataque vai de soco a cadeirada. Folha de São Paulo. http://www1.folha.uol.com.br/educacao/2017/09/1919146-sp-tem-quase-2-professores-agredidos-ao-dia-ataque-vai-de-soco-a-cadeirada.shtml

Quintana, S. C. R. (2010). A trajetória do município de Campinas para a adoção da Justiça Restaurativa. [Dissertação de Mestrado, Universidade Bandeirante de São Paulo]. http://www.uniban.br/pos/farmacia/teses/silmara.pdf

Sacavino, S. \& Candau, V. M. (2008). Sociedade, Direitos Humanos e Cidadania: desafios para a educação no Brasil. In S. Sacavino \& V. M. Candau (Orgs.). Educação em Direitos Humanos: temas, questões e propostas (pp. 10-51). DP et ALLI.

Schilling, F. (2014). Educação e direitos humanos: percepções sobre a escola justa. Cortez.

Secretaria Especial de Direitos Humanos da Presidência da República. (2009). Programa Nacional de Direitos Humanos (PNDH - 3). https://direito.mppr.mp.br/arquivos/File/PNDH3.pdf

Sindicato dos Professores do Ensino Oficial do Estado de São Paulo. (2014). Violência nas escolas: o olhar dos professores. http://www.apeoesp.org.br/publicacoes/observatorio-da-violencia/apeoesp-apresenta-dados-de-nova-pesquisa-sobre-violencia-nas-escolas/

Sindicato dos Professores do Ensino Oficial do Estado de São Paulo. (2017). Sob gestão Alckmin, escolas estaduais vivem escalada da violência. http://www.apeoesp.org.br/publicacoes/observatorio-da-violencia/sob-gestao-alckmin-escolas-estaduais-vivem-escalada-da-violencia/

Sindicato dos Professores do Ensino Oficial do Estado de São Paulo. (2019). Pesquisa indica aumento de casos de violência nas escolas públicas de São Paulo. http://www.apeoesp.org.br/noticias/noticias-2019/pesquisa-indica-aumento-de-casos-de-violencia-nas-escolas-publicas-de-sao-paulo/

Scuro Neto, Pedro. (2008). O enigma da esfinge: uma década de justiça restaurativa no Brasil, 12(23), 3-24. https://proxy.furb.br/ojs/index.php/juridica/article/view/833

Slakmon, C, Vitto, R. C. P. \& Pinto, R. S. G. (2005). Prefácio. In C. Slakmon, R. C. P. Vitto \& R. S. G. Pinto (Orgs.). Justiça Restaurativa (pp. 13-16). Ministério da Justiça, Programa das Nações Unidas para o Desenvolvimento [PNUD]. https://www.ufpe.br/ppgdh/images/documentos/jrestaurativa.pdf

Viana Orta, M. I. (2019). 25 años de Mediación Escolar en España: 1994-2019. Cuestiones Pedagógicas. Revista De Ciencias De La Educación, (27), 11-22. https://doi.org/10.12795/CP.2018.i27.01

Waiselfisz, J. J. (2013). Homicídios e Juventude no Brasil. Brasília: Secretaria Geral da Presidência da República. http://www.mapadaviolencia.org.br/pdf2013/mapa2013_homicidios_juventude.pdf

Waiselfisz, J. J. (2014). Mapa da Violência: os Jovens do Brasil. Brasília: Secretaria Geral da Presidência da República, Secretaria Nacional de Juventude, Secretaria de Políticas de Promoção da Igualdade Racial. http://www.mapadaviolencia.org.br/mapa2014_jovens.php

Waiselfisz, J. J. (2015). Mapa da Violência 2015: Adolescentes de 16 e 17 anos do Brasil. Faculdade Latino-Americana de Ciências Sociais [FLACSO]. http://www.mapadaviolencia.org.br/mapa2015_adolescentes.php 